\title{
Public Support for the Judicial Branches Under the COVID-19 Pandemic*
}

\author{
Sohei Shigemura ${ }^{\dagger} \quad$ Tatsuya Iseki $^{\ddagger}$ Shun Ikeda ${ }^{\S}$ Hideo Ishima ${ }^{\llbracket}$
}

August 29, 2020

\begin{abstract}
In democratic countries, public support for the judiciary is crucial to prevent abuse of power by the government. While facing the coronavirus disease 2019 (COVID-19) pandemic, governments may overly restrict their citizens' rights to prevent the spread of infectious diseases. This study examined whether voters would support a court's ruling if the court decided that the government's restriction of their rights was illegal and nullified the risk-averse policies. We suppose that voters faced with the risk of a pandemic will support a government with the expertise and resources to prevent a pandemic, and we set up the following hypotheses: If the courts nullify the measures against COVID-19, the public will not support the courts, and the government's failure to comply with the court's ruling will not diminish support for the government. We find support for these hypotheses in the contexts wherein the degree of restriction on voters' rights is weak. Because there is a close relationship between "public support for the court" and "government abuse of power," we need to consider which factors determine support for the court.
\end{abstract}

Keywords: Judicial Politics, Survey Experiment, COVID-19

3,108 Words (exclude Tables \& Figures)

\footnotetext{
${ }^{*}$ Acknowledgement

${ }^{\dagger}$ Kobe University (shigemura@hawk.kobe-u.ac.jp)

${ }_{\ddagger}^{\ddagger}$ Kyoto University (tatsuya.iseki71@gmail.com)

§Kyoto University (ikeda.syun.46c@st.kyoto-u.ac.jp)

`Kyoto University (hideo.ishima@gmail.com)
} 


\section{Introduction}

As the coronavirus disease 2019 (COVID-19) pandemic spread worldwide, many democratic governments decided to take strong pandemic-control measures that are unthinkable under ordinary situations. Although these measures, such as stay-at-home orders called "lockdown," have proven effective, they also impose a high degree of burden on citizens. Considering some former democracies are backsliding to autocracies while responding to this pandemic (Edgell et al., 2020), governments' abuse of pandemic-control measures is a serious concern.

One important mechanism preventing a backslide to autocracy is the legal check-andbalance of independent judicial branches (Gibler and Randazzo, 2011). However, with neither the purse nor sword to implement their rulings, judicial branches need public support of the courts to prevent governments from abusing their power (Gibson, Caldeira, and Baird, 1998). Under ordinary democracies, this would actually work. Since peo-

ple generally attribute high legitimacy to judicial branches (Gibson, Caldeira, and Baird, 1998), they punish incumbents for judicial non-compliance through elections (Krehbiel, 2020). The fear of the electoral backlash against judicial non-compliance incentivizes governments to comply with the courts' rulings even when they are against the governments' interest (Vanberg, 2004; Staton, 2010).

An important question here is whether these mechanisms work even during the COVID-19 pandemic. Do people believe the judicial branches when they rule on matters related to pandemic control? Do they electorally punish incumbents if incumbents ignore the court's rulings?

On one hand, many people are concerned with the negative outcomes of pandemiccontrol measures. Their concerns actually lead to legal disputes. For instance, a large number of constitutional complaints against lockdown measures were filed with the Federal Constitutional Court (FCC) of Germany. Although the FCC ruled that these measures were constitutional, this indicated that the FCC was willing to protect individual rights 
from the abuse of pandemic-control measures. This anecdote shows that people expect judicial branches to prevent abuse of pandemic-control authority, and courts are willing to respond to this expectation.

On the other hand, most people seem to accept the burden caused by pandemiccontrol measures, which they would not have accepted before the pandemic. Considering the uncertain risk of this pandemic and the fact that courts usually lack specific knowledge required to prevent a pandemic, it is plausible that people switch their reliance from judicial branches to the governments. If so, they may tolerate governments' non-compliance with judicial decisions related to COVID-19.

Thus, we hypothesize that the COVID-19 pandemic changed the nature of public support for judicial branches. Faced with the risk of a pandemic, voters show conformity to the governments, which possess expertise and resources to prevent a pandemic. This leads to two empirically testable predictions. Nullifying pandemic-control measures undermines public support for the courts (H1). As for COVID-19 related issues, noncompliance with the courts' rulings does not decrease electoral support for the governments $(\mathrm{H} 2)$.

We also hypothesize that voters do not blindly accept the governments' measures. As the cost of pandemic-control measures increases, they come to expect the judicial branches to play active roles. Therefore, when the cost of pandemic-control measures is high, nullifying pandemic-control measures does not result in a decline in public support for judicial branches (H3). In this case, governments' non-compliance with court rulings is electorally punished (H4).

To test these hypotheses, we conducted a survey experiment from June 8 to June 12, 2020, in Japan. Japan was, at least at that time, a good case to examine. The future of Japanese pandemic control was quite unclear at that time. While the Japanese government lifted the state of emergency declaration on May 25 in response to the decline in the reported COVID-19 infections, there existed concern about the next wave of the pan- 
demic, which later became a reality. At the same time, there actually existed a concern about the negative effects of the government's pandemic-control measures: from economic loss to unreasonable constraints on civil liberty.

If it is clear that a severe pandemic cannot be avoided, people would not let the courts suspend any pandemic-control measures. On the other hand, if it is clear that the pandemic is already successfully avoided, there would be no room to accept costly pandemiccontrol measures. Japanese voters, who faced the uncertain risk of both the pandemic and negative effects of pandemic-control measures, are suitable subjects for testing the questions.

We found evidence that supports $\mathrm{H} 1$ and $\mathrm{H} 2$. Ruling a pandemic-control measure as illegal undermines public support for judicial branches, and non-compliance with court rulings does not result in electoral loss.

We also found that, at least for the public support for judicial branches, voters do not blindly accept the cost of pandemic-control measures. When the degree of constraint on civil liberties is high, the courts' nullifying of pandemic-control measures does not reduce public support, in line with H3. However, we hardly found evidence supporting H4.

\section{Research Design}

\subsection{Outline of the Survey Experiment}

We conducted an online survey experiment from June 8 to June 12, 2020, in Japan. ${ }^{1}$ The subjects of this experiment included 2,852 Japanese adults registered with Yahoo! Crowdsourcing, ${ }^{2}$ a major Japanese crowdsourcing service similar to Amazon Mechanical Turk. Previous studies have used this service to conduct a survey experiment with Japanese

\footnotetext{
${ }^{1}$ This survey experiment was approved by the Institutional Review Board of Kobe University, Graduate School of Law (Approval number: 020001).

${ }^{2}$ See https: //crowdsourcing.yahoo.co.jp/ for detailed information about this service.
} 
subjects (Asaba et al., 2020; Matsumura and Tago, 2019). ${ }^{3}$

At that time, although the Japanese government lifted the state of emergency declaration without enforcement on 25 May, 2020, it was not entirely clear if the pandemic was successfully controlled in Japan. There was also anxiety about whether the pandemiccontrol response would allow the government to abuse its power ${ }^{4}$ or cause an economic crisis. Japanese people were then faced with a trade-off between pandemic control and their civil liberties, while the risks of both the pandemic and unreasonable constraints on their liberties were uncertain.

The survey experiment had the following structure. First, we asked socioeconomic and demographic questions regarding, for instance, age, sex, income, and residential area. ${ }^{5}$ Second, we randomly assigned the respondents a treatment (scenario) and asked multiple questions. Third, we asked questions about political attitudes more generally, including party identification, ideology, and political efficacy. The respondents were free to withdraw from the survey at any time.

\subsection{Treatment Variable}

In this study, we created scenarios by combining the government's responses to the COVID-19 pandemic (hypothetical contexts) and the court's ruling on these responses (treatment conditions). First, we created four hypothetical contexts based on a real-life situation. In many countries, the government restricts citizens from leaving their homes to control the spread of COVID-19. Because behavioural constraints can deprive citizens economically, the government needs to provide economic compensation. In this experi-

\footnotetext{
${ }^{3}$ We first obtained 3,103 respondents. However, we dropped 251 who had answered the question twice or were satisficers.

${ }^{4}$ Kenji Ishikawa, a constitutional legal scholar from the University of Tokyo, mentioned this risk (Asahi Shimbun, 19 April 2020. [Last accessed: 19 August 2020])

${ }^{5} \mathrm{We}$ calculated the standardized bias to check whether the covariates were balanced between the experimental groups. If the bias is below 0.25 (absolute value), the covariates are balanced (Ho et al., 2007). In our sample, nearly all the covariates met this criterion (Figure 4), and so we interpret the covariates as balanced. The standardized bias is calculated by cobalt.
} 
ment, we created hypothetical contexts by combining the government's restrictions and financial support availability. These hypothetical contexts allow us to understand how voters react differently depending on the degree of restrictions on their rights.

Second, we created three treatment conditions. In the abovementioned circumstances, a citizen group might file an action with a court, claiming that the government's restrictions on their rights are illegal. Subsequently, the court can decide on the government's response as legal or illegal. Then, the government can decide whether to comply with the court's decision.

The control is the "Legal" scenario, in which the court upholds the government's order, and therefore the government does not need to decide whether to comply with the decision. Comparing the other two "Illegal\&Compliance" and "Illegal\&Non-compliance" scenarios with the control scenario allows us to examine how voters evaluate the court's challenge to the government and the government's reaction to the judicial branch.

Taken together, we created four hypothetical contexts and three treatment conditions for a total of 12 scenarios. We randomly assigned the scenarios to the respondents. Then, we estimated the treatment effects in each context. If the respondents believe that the government and public do not have to comply with illegal rulings, they have low confidence in the courts. The actual scenarios displayed to the subjects are as follows.

A large-scale outbreak of COVID-19 has been reported in neighbouring countries of Japan. There are now concerns about the spread of the virus in Japan as well.

To stop the spread of the virus, the Japanese government declared an encouragement to stay at home without enforcement [or a stay-at-home order with enforcement]. It is predicted that this declaration will cause economic stagnation and a decline in our income. Therefore, the government plans to provide benefit money of 100,000 yen [or However, the government plans not to provide benefit money].

A group claiming that the government's declaration is illegal has filed a suit with 
a court requesting the court to nullify the government measure.

- CONTROL (Legal): The court declared that the government's pandemiccontrol measure is legal.

- tREATMEnt 1 (Illegal\&Compliance): The court declared that the government's pandemic-control measure is illegal. The government followed the judgement and rescinded the declaration.

- tREATMEnt 2 (Illegal\&Non-compliance): The court declared that the government's pandemic-control measure is illegal. The government did not follow the judgement and sustained the declaration.

The number of respondents in each experimental group can be found in Table 1.

\subsection{Outcome Variable}

The first outcome variable is the public support for the judicial branch. According to Bartels and Kramon (2020), there are two types of judicial power; horizontal power, which is judicial power over the public, and vertical power, which is judicial power over the incumbents. To measure the court's support in both horizontal and vertical dimensions, we ask the following questions.

- Support for Horizontal Power: Do you agree with the idea that the government should comply with a judicial decision?

- Support for Vertical Power: Do you agree with the idea that we should comply with a judicial decision?

The respondents were asked whether the government should follow the judgement on a five-point scale:

1. I disagree 
2. I somewhat disagree

3. Neither

4. I somewhat disagree

5. I agree

The second outcome variable is the electoral support for the government party, Liberal Democratic Party (LDP), which complied with or invaded the court's ruling. Extant literature predicts that, at least in democracies under ordinary circumstances, invasion of a court's ruling lowers electoral support for the government party. However, it is not clear whether voters will support the government when the government ignores the court's decision or the government's policy is ruled illegal. Therefore, we asked the participants' voting intention as follows:

Q3 Suppose an election is being held in two weeks. Which party would you vote for?

Respondents selected one party from the list below:

- Liberal Democratic Party (LDP)

- The Constitutional Democratic Party of Japan (CDP)

- Democratic Party For the People (DPFP)

- Komeito

- Japan Innovation Party

- Japanese Communist Party (JCP)

- Social Democratic Party (SDP)

- The Party to Protect the People from NHK

- Reiwa Shinsengumi

- Other Party

- Do not want to answer

We are interested in the effect of our treatment on the vote for the government party. Therefore, we coded the response as a binary variable that takes the value of one if the respondents intend to vote for LDP and zero otherwise. 


\subsection{Estimation}

We estimated the treatment effects for each hypothetical scenario. As already mentioned, we created four hypothetical contexts and hypothesized voter's evaluation of the court's ruling and the government's reaction to the ruling varies in each context. Moreover, we set three outcome variables. Therefore, we estimate $12(4 \times 3)$ regression models.

To estimate the treatment effects on the support for horizontal power and vertical power, we use an ordinary least squares regression (Equation 1):

$$
Y_{i, c}=\alpha_{i, c}+\beta_{1} \text { Illegal-Compliance }_{i, c}+\beta_{2} \text { Illegal-Invasion }_{i, c}+\epsilon_{i, c}
$$

where $Y_{i, c}$ indicates the outcome variables Support for Horizontal Power and Support for Vertical Powerby respondent $i$ in context $c$; Illegal-Compliance $i, c$ is a dummy variable that equals one if respondent $i$ sees the scenario wherein the court ruled that the government's response was illegal, and the government complied with the ruling in context $c$; Illegal-Invasion ${ }_{i, c}$ is a dummy variable that equals one if respondent $i$ sees the scenario wherein the court ruled that the government's response was illegal, and the government invaded the ruling in context $c$; and $\beta_{1}$ and $\beta_{2}$ are the coefficients. We estimated the coefficients to show the treatment effects.

Besides, we examined the treatment effects on the support for the government party. We used a logistic regression because the outcome variable is binary. Then, we supposed that

$$
\begin{aligned}
Y_{i, c} & \sim \operatorname{Bernoulli}\left(\theta_{i, c}\right), \\
\theta_{i, c} & =\operatorname{logit}^{-1}\left(\alpha_{i, c}+\beta_{1} \text { Illegal-Compliance }_{i, c}+\beta_{2} \text { Il legal-Invasion }_{i, c}\right),
\end{aligned}
$$

where $Y_{i, c}$ is the Support for the Government Party by respondent $i$ in context $c ; \theta_{i, c}$ is the probability of respondent $i$ 's voting for the government party in context 


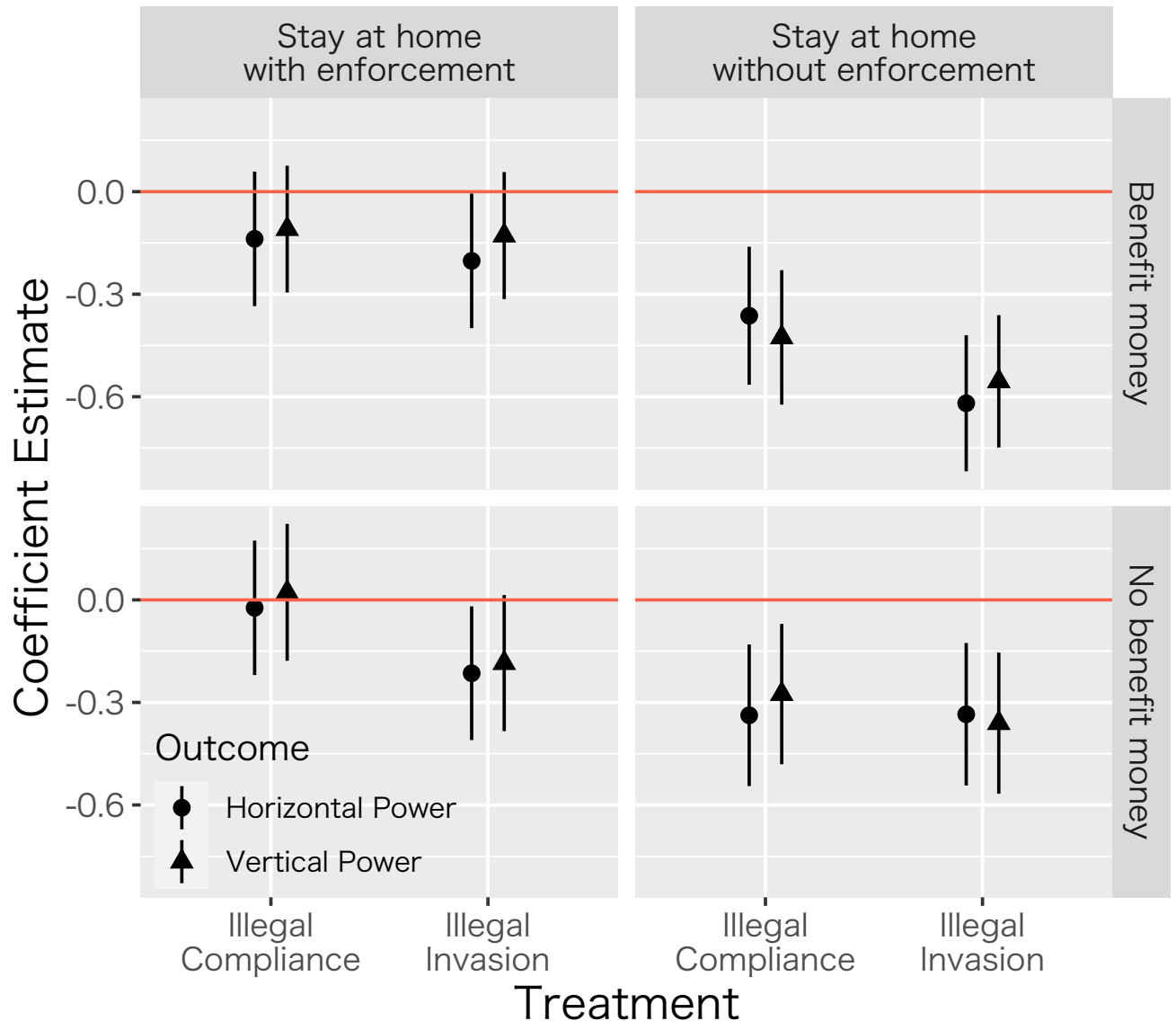

Figure 1: Estimation Results of the Ordinary Least Squares Model

Note: This plot shows the treatment effects on the support for the judicial power. The outcome variables are the support for horizontal power $(\bullet)$ and vertical power $(\mathbf{\Lambda})$. The horizontal axis represents treatment conditions. The vertical axis indicates the coefficient estimates. The dots in the figure represent point estimates. The vertical lines show 95\% confidence intervals.

c; Illegal-Compliance $i, c$ and Illegal-Invasion ${ }_{i, c}$ are treatment variables for respondent $i$ in context $c$; and $\beta_{1}$ and $\beta_{2}$ are the coefficients.

\section{Results: Treatment Effects of the Scenarios}

Figure 1 shows the treatment effects on the support for horizontal power and vertical power. As the figure shows, the court tends to lose the support of voters when it rules that the government's response to emergencies is illegal. In particular, the respondents 
oppose the court's decision in the scenario wherein the court declares that an unenforced stay-at-home order is illegal. Moreover, in scenarios wherein the courts make a forced stay-at-home order illegal, the respondents also oppose the court's decision. Still, this tendency is uncertain because the $95 \%$ confidence intervals contain the value of zero.

The results here seem to, at least partly, support H1 and H3. In scenarios wherein the court nullifies the government's encouragement to stay at home, as predicted in H1, respondents' support for the judicial power declines. However, in the scenario wherein the court makes the stay-at-home order with enforcement illegal, respondents' support for the court mostly remains unchanged. Consistent with $\mathrm{H} 3$, wherein the constraint on civil liberties is significant, respondents continue to support the court when the court rules the government's measure as illegal. Interestingly, however, we can hardly see the difference between the scenarios wherein the court rules as illegal a forced order with benefit money and a forced order without benefit money. Moreover, little difference can be observed between the scenarios wherein encouragement with benefit money is ruled illegal and one in which encouragement without benefit money is nullified. This implies that although the extent of constraint on their civil liberties affects how respondents choose between the government's pandemic control and judicial protection of individual rights, compensation for economic loss has no or only limited effect on respondents' evaluation of the judicial branch.

There is one exception in the scenario wherein the court rules that a forced order with no benefit money is illegal but the government refuses to comply with the court's decision. In this case, although the estimated effect is small, support for the judicial branch declines in both vertical and horizontal dimensions. This may indicate, as judicial politics literature supposed, that the government's non-compliance hurts the court's legitimacy, leading to a decline in public support for the judicial branch.

Figure 2 presents the results of the logit model estimation. The scenario wherein the court ruled that it was illegal for the government to declare a stay-at-home order without 


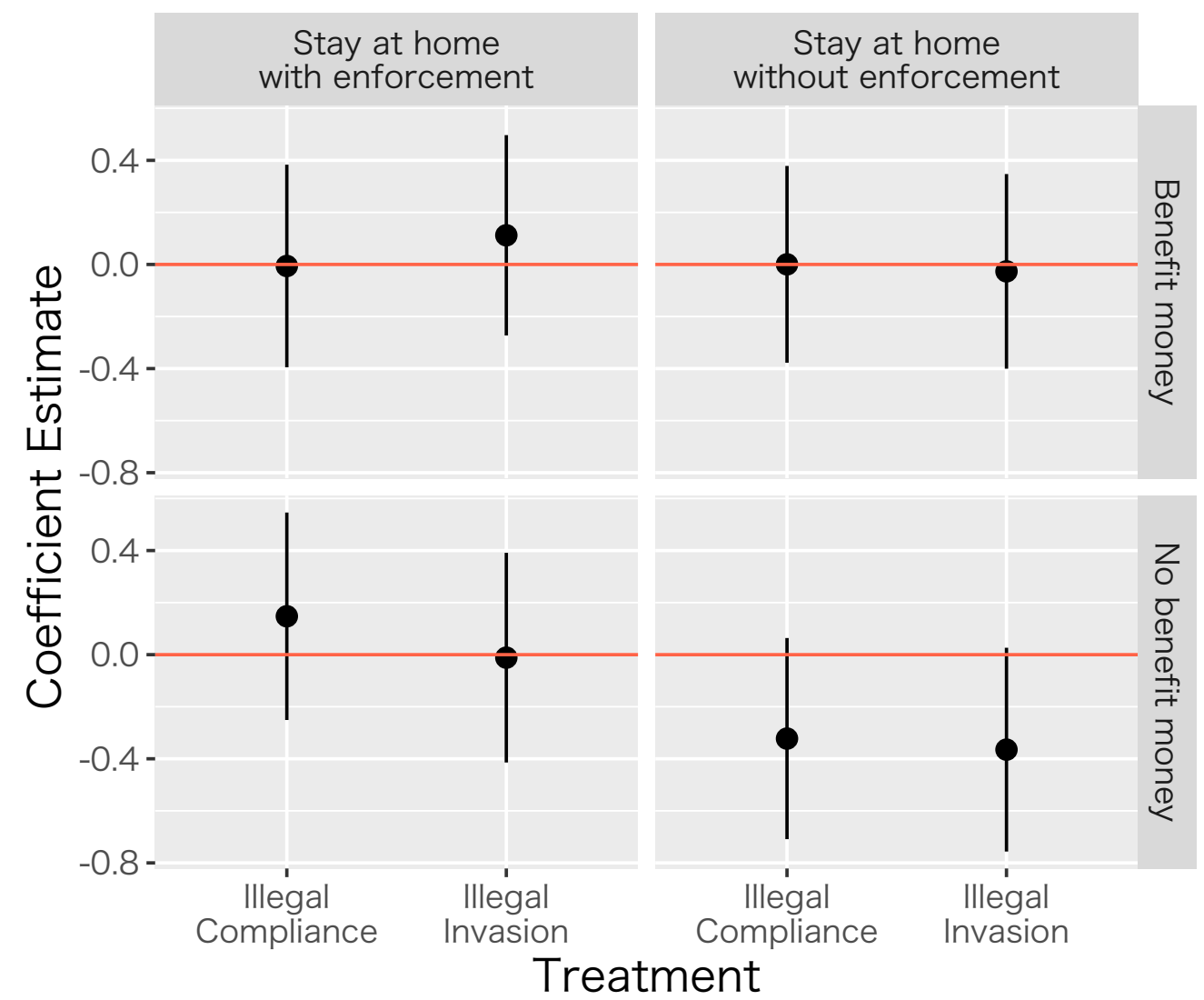

Figure 2: Estimation Results of the Logit Model

Note: This plot shows the coefficient estimates of Equation 2. The dots in the figure represent mean predicted probabilities of voting for the government party. The horizontal axis represents treatment conditions. The vertical axis indicates the predicted probabilities of voting for the government party.

enforcement and not provide benefit money affects the support for the government party. Even though the effects are not statistically significant, the substantive effects are not negligible.

Figure 3 displays the predicted probabilities of voting for the government party. We find that the respondents were more likely to not vote for the government party only if they were required to stay at home without enforcement but could not get financial support. In particular, if the government continues to ignore court rulings and enforce its policies, it will lose support from voters-the probability of voting for the government 


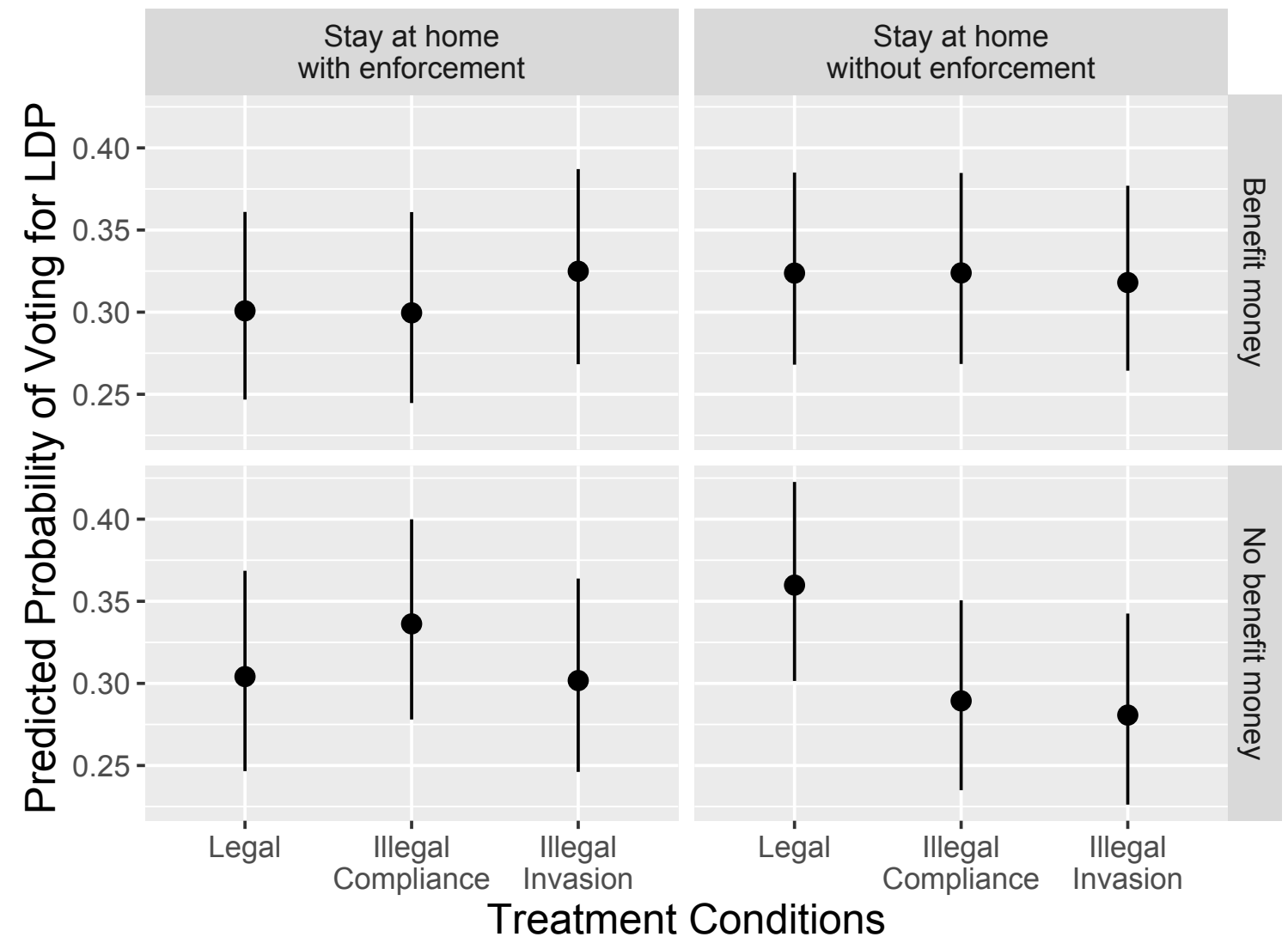

Figure 3: Predicted Probabilities of Voting for the Government Party

Note: This plot shows the predicted probabilities of voting for the government party. The dots in the figure represent mean predicted probabilities, the horizontal axis represents treatment conditions, and the vertical axis indicates the predicted probabilities of voting for the government party.

party drops by about 7 percentage points, which could change the result of the election. Except for this result, the government party is less likely to lose support from voters if they ignore the court's ruling in an emergency.

Again, $\mathrm{H} 2$ is supported. In three of the four scenarios, neither a legal dispute against the government's measure nor the government's non-compliance causes electoral loss. This implies that, contrary to voters in ordinary democracies, voters tolerate the government's judicial non-compliance to maintain pandemic-control measures.

On the other hand, we find that H4 is hardly supported. Filing a suit against the gov- 
ernment and non-compliance lead to electoral loss only when the government encourages citizens to stay at home WITHOUT enforcement and does not provide benefit money. Inconsistent with the result about public support for the courts, voters seem to penalize the incumbent government for defeat in a legal dispute and non-compliance only when the government's unenforced stay-at-home encouragement without benefit money is ruled illegal. Considering that the voters do not switch their electoral support when a forced order without benefit money is struck down, lack of compensation may not be the cause of electoral backlash.

One possible explanation is that respondents' risk perception is endogenous to the government's reaction to the pandemic. When the government neither declares a stayat-home order with enforcement nor provides benefit money, the level of reaction is the lowest. Put differently, this scenario is most similar to the ordinary situation wherein noncompliance leads to electoral loss. This similarity may cause respondents to lower their support for the incumbent government due to non-compliance (and defeat in the trial).

In the control and illegal non-compliance groups, respondents should be able to imagine the same situation. Nevertheless, there is a gap in the probability of voting for the government party. These results suggest that respondents are opposed to governments that restrict their freedom of action but do not provide financial support, but they also have a negative image of the government because it has lost to unreliable courts.

\section{Conclusion and Discussion}

This study analysed how voters evaluate the court's legal check against the government's pandemic-control measures as well as the government's reaction to a court's ruling. Our survey experiment provided evidence that, unlike under ordinary situations, voters support the government rather than the judicial branch when a court's ruling is against the government's pandemic-control measure. Therefore, respondents refrain from penalizing 
the incumbent for non-compliance with a court's ruling.

Considering that some democracies are backsliding to autocratic regimes due to the COVID-19 pandemic, and the judicial branch plays a crucial role in protecting democracy, our findings may seem bad news for democracies under the pandemic. However, at least regarding public support for the judicial branch, we found evidence that voters reasonably monitor the government's reaction to the pandemic. Nullifying the government's pandemic-control measures did not cause respondents' judicial support to decline in a scenario wherein a forced stay-at-home order is ruled illegal. This implies that voters reasonably assess the constraints imposed on their liberties. If they believe the constraint is severe, they let the judicial branch rule against the government.

One concern is about the electoral reaction to governments that failed to comply with a court's ruling. Unlike our H4, non-compliance with a court's ruling leads to electoral loss only when unenforced encouragement is ruled illegal. As mentioned above, this may be because such a low-level government measure makes respondents believe that the risk of the pandemic is also low. How the government's reaction to the pandemic affects voters' risk perception itself is an important question that future works should examine.

Finally, we briefly discuss the findings' external validity. We conducted our experiment in Japan, a well-developed democracy. Considering that judicial branches in new democracies are struggling to acquire public support (Gibson and Caldeira, 2003), H1 may hold in new democracies. However, whether the results for $\mathrm{H} 3$ are observed in new democracies is unclear. The form of the order for pandemic control is also important. We employed the case of a stay-at-home order/encouragement, which, we believe, is the most understandable example for ordinary voters. It is reported that the most widely observed violation of the democratic standard is a constraint on freedom of speech (Edgell et al., 2020). Future study should also examine how voters react when the government's pandemic-control measures that constrain freedom of press are ruled illegal. 


\section{References}

Asaba, Yuki, Kyu S. Hahn, Seulgi Jang, Tetsuro Kobayashi, and Atsushi Tago. 2020. “38 Seconds above the 38th Parallel: How Short Video Clips Produced by the US Military Can Promote Alignment despite Antagonism between Japan and Korea." International Relations of the Asia-Pacific 20(2): 253-273.

Bartels, Brandon L., and Eric Kramon. 2020. “Does Public Support for Judicial Power Depend on Who Is in Political Power? Testing a Theory of Partisan Alignment in Africa." American Political Science Review 114(1): 144-163.

Edgell, Amanda B., Sandra Grahn, Jean Lachapelle, Anna Lührmann, and Seraphine F. Maerz. 2020. “An update on pandemic Backsliding: Democracy Four Months After the Beginning of the Covid-19 Pandemic." Policy Briefs 24.

Gibler, Douglas M., and Kirk A. Randazzo. 2011. “Testing the Effects of Independent Judiciaries on the Likelihood of Democratic Backsliding." American Journal of Political Science 55(3): 696-709.

Gibson, James L., and Gregory A Caldeira. 2003. “Defenders of Democracy? Legitimacy, Popular Acceptance, and the South African Constitutional Court." Journal of Politics 65(1): $1-30$.

Gibson, James L., Gregory A. Caldeira, and Vanessa A. Baird. 1998. "On the Legitimacy of National High Courts." American Political Science Review 92(2): 343-358.

Ho, Daniel E, Kosuke Imai, Gary King, and Elizabeth A Stuart. 2007. “Matching as nonparametric preprocessing for reducing model dependence in parametric causal inference." Political analysis 15(3): 199-236.

Krehbiel, Jay N. 2020. “Do voters punish noncompliance with high courts? A crossnational analysis." Politics .

Matsumura, Naoko, and Atsushi Tago. 2019. “Negative Surprise in UN Security Council Authorization: Do the UK and French Vetoes Influence the General Public's Support of US Military Action?" Journal of Peace Research 56(3): 395-409. 
Staton, Jeffrey K. 2010. Judicial Power and Strategic Communication in Mexico. Cambridge: Cambridge University Press.

Vanberg, Georg. 2004. The Politics of Constitutional Review in Germany. Political Economy of Institutions and Decisions Cambridge: Cambridge University Press. 


\section{Appendix}

\subsection{Sample Size}

Table 1: Number of respondents by experimental group

\begin{tabular}{|c|c|c|c|c|c|}
\hline \multirow{3}{*}{$\begin{array}{l}\text { Group } \\
\text { Group1 }\end{array}$} & \multicolumn{2}{|c|}{ Context } & \multirow{2}{*}{\multicolumn{2}{|c|}{ Treatment Conditions }} & \multirow{3}{*}{$\frac{N}{237}$} \\
\hline & Stay-at-Home & Benefit Money & & & \\
\hline & Forced & Provided & Illegal-Compliance & (T1) & \\
\hline Group2 & Forced & Provided & Illegal-Invasion & $(\mathrm{T} 2)$ & 237 \\
\hline Group3 & Forced & Provided & Control & (CTRL) & 247 \\
\hline Group4 & Forced & Unprovided & Illegal-Compliance & (T1) & 229 \\
\hline Group5 & Forced & Unprovided & Illegal-Invasion & $(\mathrm{T} 2)$ & 232 \\
\hline Group6 & Forced & Unprovided & Control & $(\mathrm{CTRL})$ & 217 \\
\hline Group7 & Not Forced & Provided & Illegal-Compliance & $(\mathrm{T} 1)$ & $24 \overline{7}$ \\
\hline Group8 & Not Forced & Provided & Illegal-Invasion & $(\mathrm{T} 2)$ & 261 \\
\hline Group9 & Not Forced & Provided & Control & (CTRL) & 244 \\
\hline Group10 & Not Forced & Unprovided & Illegal-Compliance & $(\mathrm{T} 1)$ & 239 \\
\hline Group11 & Not Forced & Unprovided & Illegal-Invasion & $(\mathrm{T} 2)$ & 235 \\
\hline Group12 & Not Forced & Unprovided & Control & (CTRL) & 228 \\
\hline
\end{tabular}




\subsection{Balance Test}

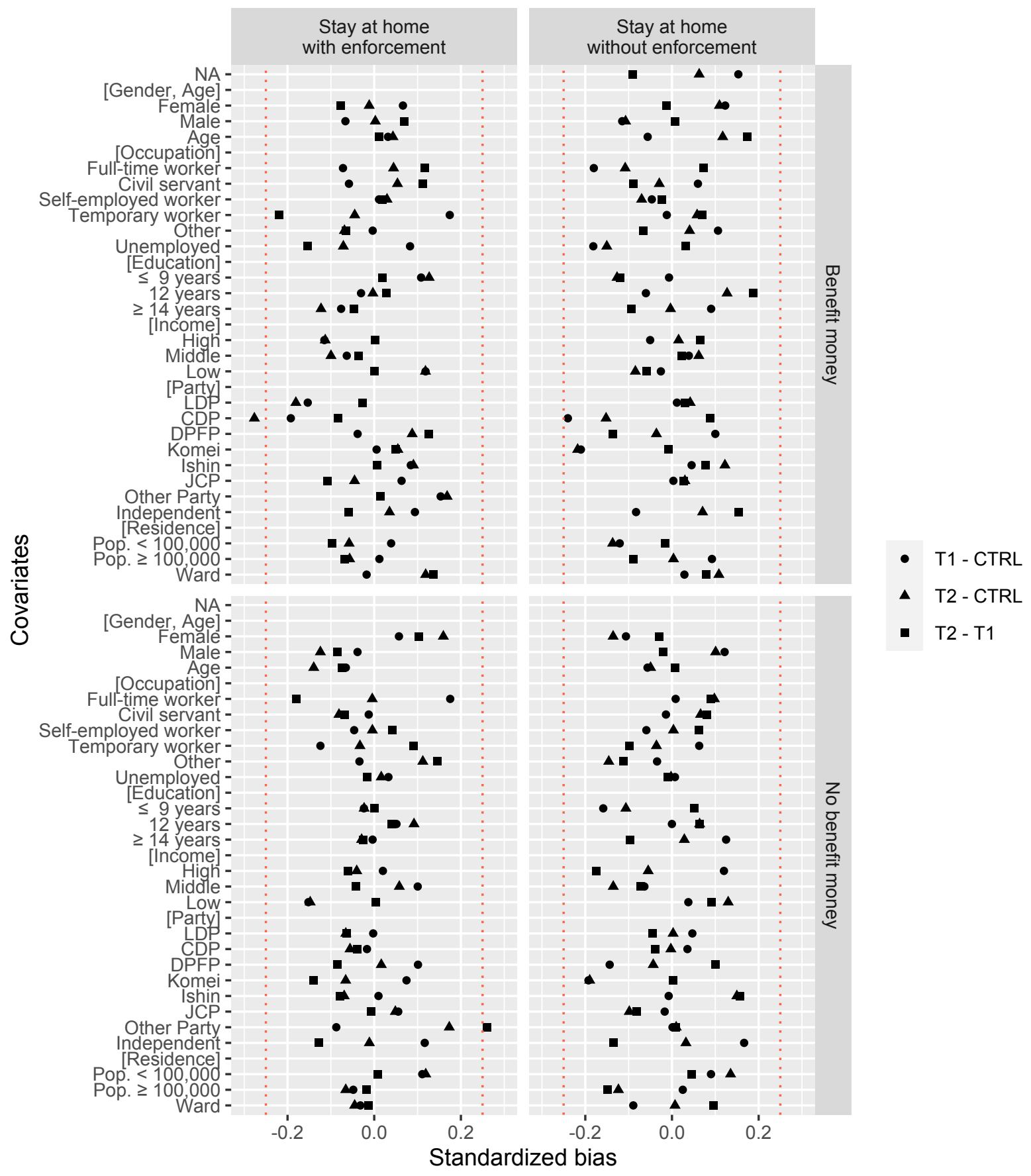

Figure 4: Standardized Bias in Each Hypothetical Context

Note: This plot shows standardized bias in each hypothetical context. The dots $(\bullet, \mathbf{\Lambda}, \mathbf{\square})$ in the figure represent standardized bias. The vertical red dashed line axis indicates the threshold for judging whether the covariates are balanced. 